\title{
Reactions to spatial and nonspatial change in two inbred strains of mice: Further evidence supporting the hippocampal dysfunction hypothesis in the DBA/2 strain
}

\author{
MARTINE AMMASSARI-TEULE and ALESSANDRO TOZZI \\ Consiglio Nazionale delle Ricerche, Rome, Italy \\ CLELIA ROSSI-ARNAUD \\ Consiglio Nazionale delle Ricerche, Rome, Italy \\ and Università di Roma "La Sapienza," Rome, Italy \\ and \\ ETIENNE SAVE and CATHERINE THINUS-BLANC \\ Centre National de la Recherche Scientifique, Marseille, France
}

\begin{abstract}
Mice belonging to the inbred $\mathrm{C} 57 \mathrm{BL} / 6$ and $\mathrm{DBA} / 2$ strains were repeatedly exposed to a given spatial configuration of five objects contained in an open field. Locomotor activity, habituation of exploration, and reactivity to the displacement of some objects (spatial change) and to the substitution of a familiar object by a new one (nonspatial change) were examined. The results show that DBA mice were more active than C57 mice and that habituation developed more rapidly in the former strain. DBA mice did not react to spatial change by an increased exploration directed toward the displaced objects, whereas C57 mice showed both an increased interest for these objects and a parallel decreased interest for the nondisplaced ones. Conversely, both strains strongly reacted to nonspatial change. These results support the hypothesis that DBA mice represent a genetic model of hippocampal dysfunction. The fact that, in these and other spatial tasks, DBA mice behave as rats with dorsal lesions of the hippocampus suggests that mice from this strain reproduce more specifically the dorsal hippocampal syndrome.
\end{abstract}

Mice of the C57BL/6 (C57) and DBA/2 (DBA) inbred strains perform differently in spatial tasks, with $\mathrm{C} 57$ mice showing better learning than DBA mice (AmmassariTeule \& Caprioli, 1985; Crusio, Schwegler, \& Lipp, 1987; Upchurch \& Wehner, 1989). Since evidence has accumulated indicating that the hippocampus was primarily involved in the processing of spatial information (see Barnes, 1988, Eichenbaum, Stewart, \& Morris, 1990, and O'Keefe \& Nadel, 1978, for reviews), much attention has been devoted to the identification of strain-dependent neurobiological differences at the hippocampal level that may subserve these different spatial learning abilities.

Anatomical studies have shown that C57 mice express a larger density of neurons in the dorsal hippocampus than do DBA mice (Wimer et al., 1976). The former strain is also characterized by a higher number of mossy fiber terminals in the hippocampal regio inferior (Barber,

This research was supported by a grant from the Centre National de la Recherche Scientifique, France, and from the Consiglio Nazionale delle Ricerche, Italy: Bilateral Project No. 790. The authors would like to thank Roberta Populin for drawing Figure 1. Correspondence should be addressed to M. Ammassari-Teule, Istituto di Psicobiologia e Psicofarmacologia, Via Reno, 1 - 00198, Rome, Italy.
Vaughn, Wimer, \& Wimer, 1974) and an elevated activity of protein kinase $\mathrm{C}$ (PKC) in the hippocampus (Wehner, Sleight, \& Upchurch, 1990). This last observation is consistent with data indicating that, in the rat, hippocampal PKC activity correlates positively with performance in the Morris water maze (Paylor, Rudy, \& Wehner, 1991). Finally, lesions to the hippocampus produce a mild impairing effect on radial maze performance of DBA mice relative to the strong effect observed in C57 mice (RossiArnaud, Fagioli, \& Ammassari-Teule, 1991).

The fact that DBA mice are impaired in spatial tasks and exhibit a number of neurobiological alterations at hippocampal level has led several authors (Douglas, 1975; Paylor, Baskall, \& Wehner, 1993) to consider DBA mice as a genetic model of hippocampal dysfunction.

It must be underlined, however, that the term spatial task refers to a variety of situations, each involving a different degree of spatial information processing: from the mere visually guided orientation to more complex maze problems requiring the development of efficient trajectories between distinct points to be visited. In the latter case, the preliminary exploration of the maze has been shown to enhance spatial learning performance (Ellen, Parko, Wages, Doherty, \& Hermann, 1982; Sutherland, 
Chew, Baker, \& Linggard, 1987), thus indicating that exploration plays a central role in the building up of spatial representations.

In nonassociative tasks, such as in an open field containing objects, exploratory responses are also fundamental to estimate the rodents' abilities to encode spatial relationships between discrete stimulus. The principle of these experiments is the following: subjects are repeatedly exposed to a given spatial configuration of objects contained in an open field. After habituation of exploration has occurred, the spatial arrangement of the objects is modified. If the animal reacts to the displacement of objects by displaying a renewal of exploratory activity, it can be assumed that the detection of spatial novelty relies on a comparison between the current perceived arrangement and a representation or stored "internal model" of the initial situation.

Several species have been tested using such a procedure: hamsters (Poucet, Chapuis, Durup, \& ThinusBlanc, 1986; Thinus-Blanc et al., 1987; Thinus-Blanc, Durup, \& Poucet, 1992), mice (Misslin, 1983; Roullet \& Lassalle, 1990), mongolian gerbils (Cheal, 1978; Wilz \& Bolton, 1971), rats (Poucet, 1989), and monkeys (Joubert \& Vauclair, 1986; Menzel \& Menzel, 1979). All display renewed exploratory reactions to spatial change, which provides evidence that the geometric arrangement of the objects is the spatial parameter preferentially encoded during exploration.

Interestingly, animals with hippocampal lesions appear to be quite unable to detect such discrete topographical changes (Poucet, 1989; Save, Buhot, Foreman, \& Thinus-Blanc, 1992; Save, Poucet, Foreman, \& Buhot, 1992; Xavier, Stein, \& Bueno, 1990); however, a nonspatial change (e.g., replacing a familiar object by a new one at the same location) still elicits reexploration in lesioned as well as in sham-operated animals (Save, Poucet, et al., 1992).

According to the assumption that DBA mice, as opposed to C57 mice, represent a model of "hippocampal dysfunction," selective deficits in reacting to the displacement but not to the substitution of objects could be expected in the former strain. This hypothesis has been tested by comparing the reactivity of $C 57$ and DBA mice to spatial and nonspatial change.

\section{METHOD}

\section{Subjects}

The subjects were $12 \mathrm{C} 57 \mathrm{BL} / 6$ and $12 \mathrm{DBA} / 2$ male mice obtained from the Charles River Co. (Como, Italy). At the beginning of the experiment, they were approximately 3 months old, and their weights ranged from 23 to $28 \mathrm{~g}$. They were housed in groups of 5 in a room with a 12:12-h light:dark cycle (lights on 0700 $1900 \mathrm{~h}$ ), with food and water freely available.

\footnotetext{
Apparatus

The apparatus (Figure 1) was a circular open field, $60 \mathrm{~cm}$ in diameter, with $20-\mathrm{cm}$-high walls made of gray plastic material and a floor painted white and divided into sectors by black lines. The open field was placed into a soundproof cubicle and surrounded by a visually uniform environment, except for a conspicuous striped
}

pattern, $20 \mathrm{~cm}$ wide and $10 \mathrm{~cm}$ high (alternating $1.5-\mathrm{cm}$-wide vertical white and black bars), attached to the wall of the field. The apparatus was illuminated by a red light $(80 \mathrm{~W})$ located on the ceiling. A video camera above the field was connected to a video recorder and a monitor.

Five objects were simultaneously present in the open field: (A) a chromium-plated parallelepiped $(7 \times 4 \times 4 \mathrm{~cm})$ with 10 holes irregularly distributed on the sides and the top; (B) a transparent Plexiglas cylinder (diameter, $8 \mathrm{~cm}$; height, $6 \mathrm{~cm}$ ); (C) a small ladder made of gray plastic material (height, $16 \mathrm{~cm}$; width, $5 \mathrm{~cm}$; number of steps, 10) inserted on a cylindrical basement (height, $2 \mathrm{~cm}$; diameter, $7 \mathrm{~cm}$ ); (D) a black Plexiglas cylinder (height, $10 \mathrm{~cm}$; diameter, $5 \mathrm{~cm}$ ) with an edge (height, $2 \mathrm{~cm}$ ) on the top; (E) a red-and-white spool (height, $12 \mathrm{~cm}$; diameter of the top and the basement, $5 \mathrm{~cm}$ ), with a small electric light bulb fixed on the top. The initial arrangement was a square with a central object (B) as schematized in Figure 1. A sixth object (F) was used to examine the reactivity to nonspatial change. It consisted of two gray iron regularly pierced squares $(10 \times 10 \mathrm{~cm})$ forming a $90^{\circ}$ angle.

\section{Behavioral Procedure}

The behavioral procedure was that described by Save et al. (1992). Mice were individually submitted to seven successive 5min sessions, each of which was separated by a 3-min delay (during which the subjects were returned to their home cage).

During Session 1, the mouse was placed into the empty open field in order to allow the animal to become familiarized with the apparatus and the baseline level of locomotor activity to be measured. During Sessions 2-4, the striped pattern and the objects were placed as in Figure 1. For Session 5, the configuration was changed by moving two objects: object $B$ replaced object $D$, which was itself displaced at the periphery of the apparatus so that the initial square arrangement was changed to a polygon-shaped arrangement during the spatial test sessions (Sessions 5 and 6 ). For Session 7, one of the familiar objects (E) was replaced by a new object $(\mathrm{F})$ at the same location.

\section{Data Collection and Analyses}

Data collection was performed using video recordings (for details see Poucet et al., 1986). Two measures were taken into account. First, locomotor activity was assessed by counting the number of sectors crossed by the animal while moving in the open field. Second, object exploration was evaluated by noting the time spent by the animal in contact with an object. A contact was defined as the subject's snout actually touching an object. In Session 5 , the total time spent by each animal in contact with the two displaced objects divided by 2 and the total time spent in contact with the three nondisplaced objects divided by 3 were recorded. Prechange interest (Session 4) toward the objects that were to be successively displaced or nondisplaced was checked in the same fashion. In Session 7, the time spent by each animal in contact with the single substituted object and the total time spent in contact with the four nonsubstituted objects divided by 4 were recorded. Prechange interest (Session 6) toward the object that was to be successively substituted and the nonsubstituted objects was checked in the same fashion.

In Session 1 (without objects), locomotor activity scores recorded in each strain were compared using a $t$ test for independent samples. From Session 2 to Session 4, the animals explored the same spatial configuration of objects. Habituation of object exploration was assessed by comparing the duration of contacts with the objects during Sessions 2, 3, and 4. A factorial analysis of variance (ANOVA) was performed on these data with session as a withinsubject factor and strain as a between-subject factor. On Session 5 , the spatial arrangement of the objects was modified. Response to the spatial change was assessed by comparing pre- and postchange data (i.e., the mean duration of contacts on Session 4 [the last session of habituation]) with the mean duration of contacts on Session 5 for each category of objects. A between-within-within 


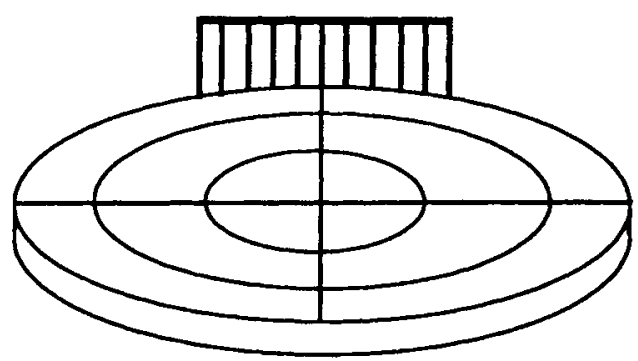

Session 1
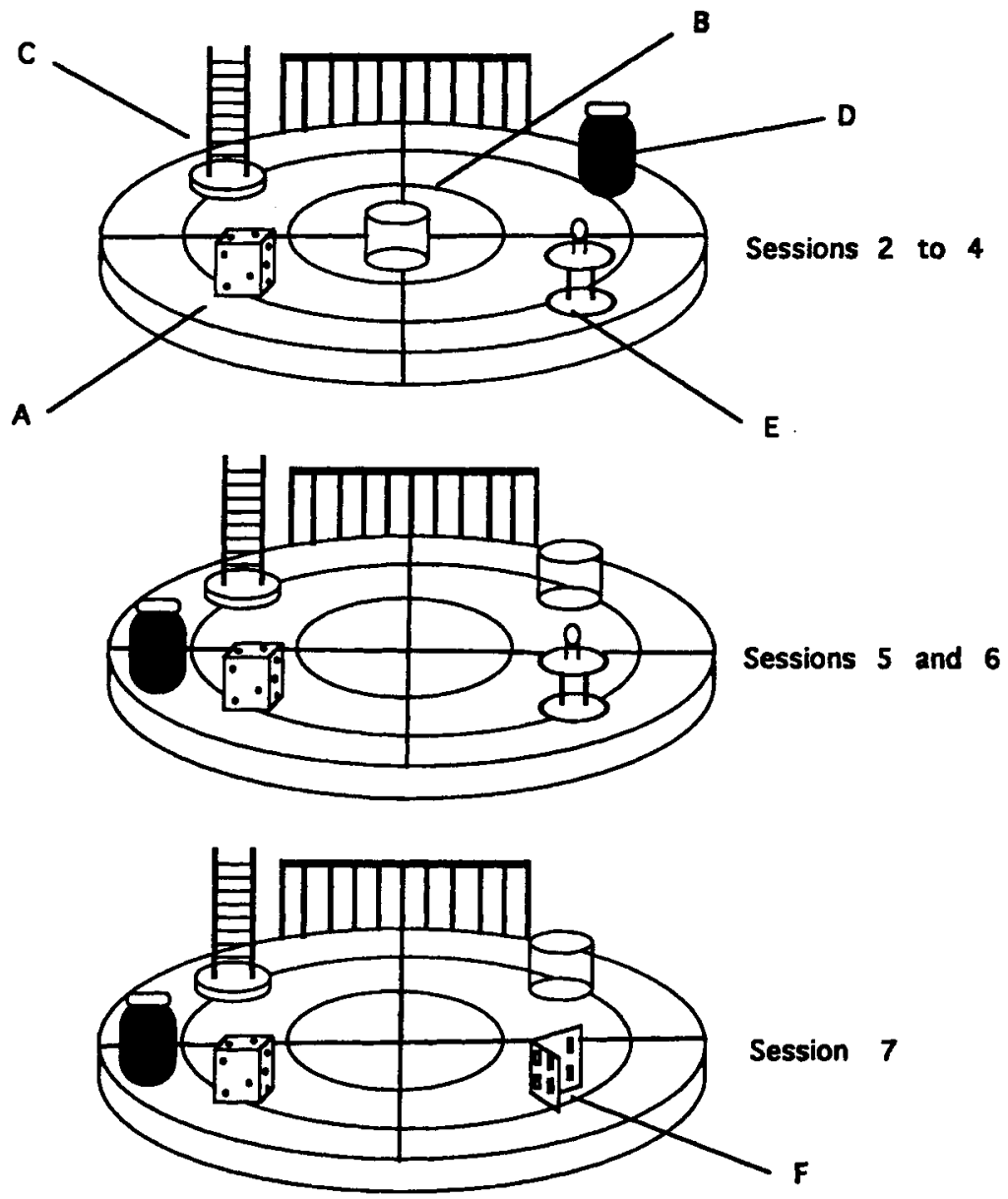

Figure 1. Schematic representation of the apparatus and the object configuration over successive sessions. The open field is initally empty (Session 1), then filled with five objects forming a particular configuration (Sessions 2-4). In Session 5, objects B and D are displaced (spatial change). In Session 7, object $E$ is substituted by object $F$ (nonspatial change).

ANOVA was performed on these data, with object category (displaced vs. nondisplaced) and session (S4, S5) as within-subject factors and strain as a between-subject factor. On Session 7 , a familiar object was replaced by a new object. Response to the new object was assessed by comparing pre- and postchange data (i.e., the mean duration of contacts with the four nonsubstituted objects) with the mean duration of contacts with the nonsubstituted object. A factorial ANOVA was performed on these data, with object category (new vs. familiar) and session (T6, T7) as withinsubject factors and strain as a between-subject factor.

\section{RESULTS}

\section{Locomotor Activity}

The locomotor activity scores of the two strains during Session 1 (without objects) are reported in Figure 2. An unpaired $t$ test performed on the mean number of crossed lines revealed that DBA mice displayed a higher level of locomotor activity than did C57 mice $[t(22)=$ $-1.74, p<.05]$. 


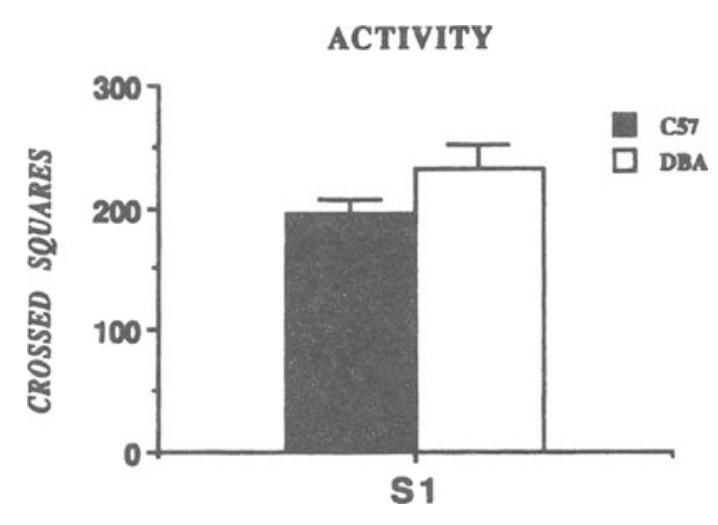

Figure 2. Locomotor activity. Mean number of lines $( \pm S E)$ crossed by mice from each strain during $5 \mathrm{~min}$ in the empty open field.

\section{Habituation}

Figure 3 represents the time course of exploratory activity from Session 2 to Session 4 in each strain. An ANOVA for repeated measures indicated a significant effect of session $[F(1,22)=1.197, p<.001]$ and of the strain $\times$ session interaction $[F(2,44)=4.143, p<.025]$. There was no significant effect of the strain factor $(p>$ .1). Both DBA and C57 mice displayed habituation of exploratory activity directed toward objects from Session 2 to Session 4 . However, the results suggest that the rate of habituation was different according to the strain. Unpaired $t$ tests aimed at comparing the mean durations of contacts with the objects in each session revealed that DBA and C57 mice differed significantly only on Session $4[t(22)=1.69, p<.005]$.

\section{Response to Spatial Change.}

Figure 4A reports the mean exploration time for displaced and nondisplaced objects in Session 5 minus the same set of data collected in Session 4. In this histogram, a positive score indicates an increased interest and a negative score indicates a decreased interest for each cate-

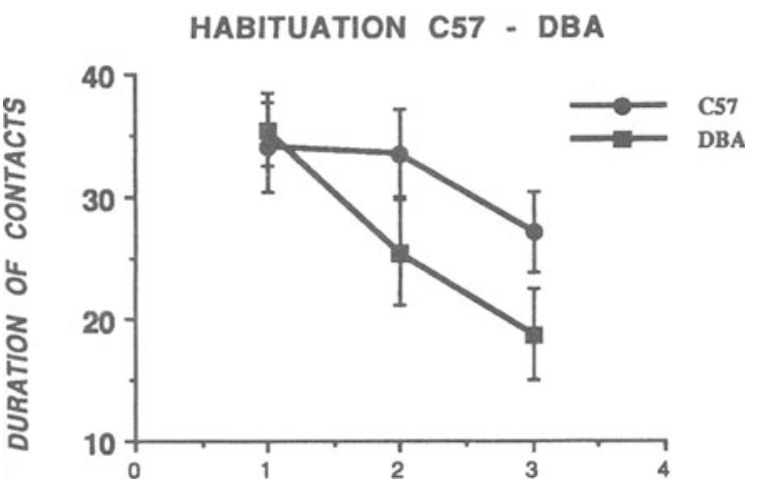

Figure 3. Habituation of object exploration. Mean duration $( \pm S E$ ) of contacts with the five objects during Sessions 2,3 , and 4 in each strain. gory of objects. Table 1 reports the mean exploration time $\pm S E$ per object category for each group in Sessions 4 and 5. An ANOVA for repeated measures revealed a significant main effect of strain $[F(1,22)=4.54, p<.05]$, a significant session $\times$ object interaction $[F(1,22)=$ $5.93, p<.05]$, and a significant strain $\times$ object $\times$ session interaction $[F(1,22)=4.46, p<.05]$. A post hoc Tukey HSD test indicated that, in Session 5, C57 mice explored the displaced objects more than the nondisplaced ones $(p<.05)$, whereas, in Session 4 , this difference did not appear. Conversely, DBA mice did not show any preference for a particular category of objects in either Session 4 or Session 5.

\section{Response to Nonspatial Change}

Figure 4B reports the mean exploration time for substituted and nonsubstituted objects in Session 7 minus the same set of data collected in Session 6. In this histogram, a positive score indicates an increased interest and a negative score indicates a decreased interest for each category of objects. Table 1 reports the mean exploration time $\pm S E$ per object for each group for Sessions 6 and 7. The data are presented graphically in Figure 4B. The statistical analysis showed a significant session $\times$ object interaction $[F(1,22)=6.46 .19, p<$ $.02]$. A post hoc Tukey HSD test indicated that, in Session 7 , mice from both strains explored the substituted object more than the nonsubstituted ones $(p<.05)$, whereas, in Session 6, this difference did not appear. Simple effects also show that, in Session 7, there was a significant difference in the mean exploration time according to the object category $[F(1,22)=6.12, p<.02]$.

\section{DISCUSSION}

This experiment was carried out to compare locomotor activity, habituation, and reactivity to spatial and nonspatial change in DBA and C57 mice. According to the "hippocampal dysfunction" hypothesis, it was expected that DBA mice but not C57 mice would have been selectively impaired in reacting to spatial change.

The results first show that, in Session 1, DBA mice explored the empty open field more than did C57 mice. This result does not agree with previous studies showing a higher rate of locomotor activity in C 57 mice (RossiArnaud \& Ammassari-Teule, 1992; Van Abeelen \& Boersma, 1984; Van Abeelen \& Van den Heuvel, 1982). Differences in testing procedure, however, may account for this discrepancy since locomotor activity was recorded for a 5-min period in this experiment instead of 8 - or 20 -min periods, as in the previous ones. It is likely that measuring locomotor activity in a new environment for a short period of time emphasizes the stress component of the behavioral response and can prevent the previously described strain-dependent exploratory tendencies to be observed. Nevertheless, the present results are consistent with the hypothesis of a hippocampal dysfunction in DBA mice since hippocampal-lesioned ani- 
(A)

RESPONSE TO SPATIAL CHANGE (S4-S5)

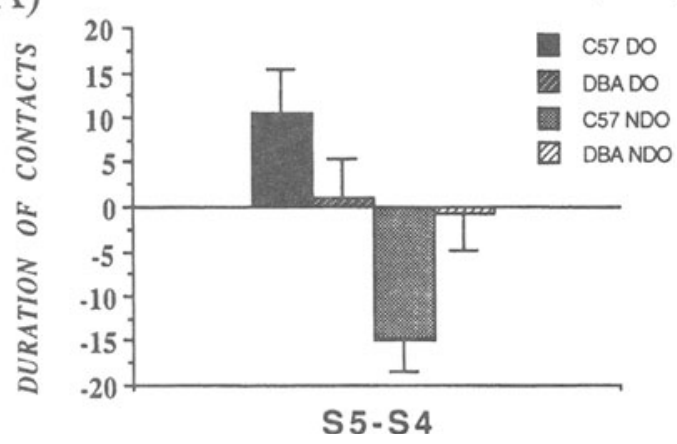

(B) RESPONSE TO NON-SPATIAL CHANGE

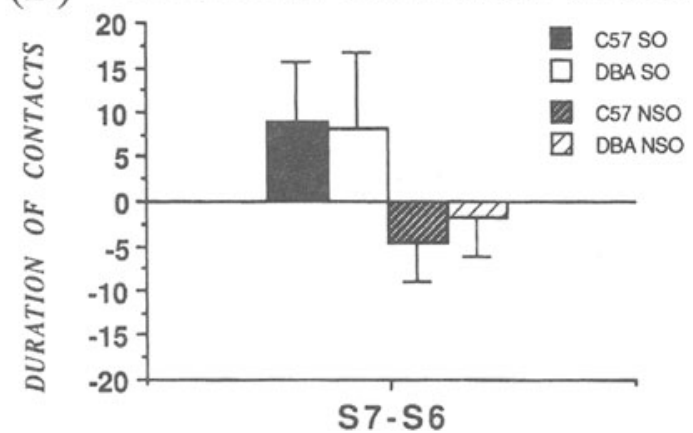

Figure 4. Reactivity to spatial (A) and to nonspatial (B) change. The histograms represent the differences in mean $( \pm S E)$ time spent (A) exploring the displaced (DO) and the nondisplaced objects (NDO) between Session 5 and Session 4 or (B) exploring the substituted object (SO) versus the nonsubstituted objects (NSO) between Session 7 and Session 6.

mals generally display an enhanced locomotor activity (Douglas \& Isaacson, 1964).

From Session 2 to Session 4, object exploration decreased in the two groups, indicating that habituation occurred in both strains. The fact that DBA mice habituate more rapidly than do C57 mice is intriguing since dysfunctions of the hippocampal system have been reported to delay or suppress the development of habituation (Gray \& McNaughton, 1983). It must be noted, however, that these reports generally refer to habituation tested in an empty open field. Indeed, habituation to a configuration of five objects requires that the subjects process information on both the objects' features and their geometric arrangement. In the present experiment, the slow habituation observed in the C57 strain could be due to the fact that these mice process information on the whole components of the experimental situation. Conversely, the rapid habituation of DBA mice may be the result of a specific processing of information related to the physical properties (shape contrast, colors, etc.) of the objects. This hypothesis may explain why DBA mice were not impaired in reacting to nonspatial change. In fact, in Session 7, the new object was actively and similarly explored by mice from the two strains. Interestingly, DBA mice and rats with dorsal lesions of the hippocampus behave in a very similar fashion in this situation: both display habituation of exploration and react to nonspatial change (Save, Poucet, et al., 1992; Xavier et al., 1990).
It is worth mentioning that the results of habituation and reactivity to nonspatial change also demonstrate that DBA mice do not have general memory impairments since these two processes rely on a comparison between the current situation and a stored representation of the previous one (Gray, 1984).

Expected strain differences in responding to spatial change clearly emerged in Session 5. DBA mice did not react to the displacement of objects, whereas C 57 mice showed both an increased interest for these objects and a parallel decreased interest for the nondisplaced ones. This result fully supports our working hypothesis and confirms the parallelism existing between DBA mice and rats with dorsal lesions of the hippocampus (Save, Poucet, et al., 1992). It is interesting to note that C57 mice discriminate better between displaced and nondisplaced objects than do nonlesioned rats.

Nevertheless, although DBA mice did not show any preference for a particular category of objects in Session 5 , they still explored the displaced and nondisplaced objects at a rate equivalent to that recorded in Session 4. This result may indicate that a limited perception of spatial change occurred in that strain, which did not elicit a renewal of exploration but, merely, a blockade of habituation.

Taken together, our results demonstrate that DBA mice are impaired in updating allocentric spatial relationships. Since this capability, which ensures behav-

Table 1

Mean Exploration Times (in Seconds) and Standard Errors ( \pm ) for Displaced Objects (DO) and Nondisplaced Objects (NDO) in Sessions 4 and 5 and Substituted Objects (SO) and Nonsubstituted Objects (NSO) in Sessions 6 and 7

\begin{tabular}{|c|c|c|c|c|c|c|c|c|c|c|c|c|c|c|c|c|}
\hline \multirow[b]{4}{*}{ Strain } & \multicolumn{8}{|c|}{ Spatial Change } & \multicolumn{8}{|c|}{ Nonspatial Change } \\
\hline & \multicolumn{4}{|c|}{ Session 4} & \multicolumn{4}{|c|}{ Session 5} & \multicolumn{4}{|c|}{ Session 6} & \multicolumn{4}{|c|}{ Session 7} \\
\hline & \multicolumn{2}{|c|}{ DO } & \multicolumn{2}{|c|}{ NDO } & \multicolumn{2}{|c|}{ DO } & \multicolumn{2}{|c|}{ NDO } & \multicolumn{2}{|c|}{$\mathrm{SO}$} & \multicolumn{2}{|c|}{ NSO } & \multicolumn{2}{|c|}{ SO } & \multicolumn{2}{|c|}{ NSO } \\
\hline & $\bar{M}$ & $S E$ & $M$ & $S E$ & $M$ & $S E$ & $M$ & $S E$ & $M$ & $S E$ & $M$ & $S E$ & $M$ & $S E$ & $M$ & $S E$ \\
\hline $\mathrm{C} 57$ & 24.96 & 4.54 & 30.5 & 4.75 & 35.58 & 5.77 & 15.72 & 2.17 & 11.25 & 6.37 & 22.15 & 5.37 & 20.33 & 3.75 & 16.01 & $3 . \overline{48}$ \\
\hline DBA & 17.54 & 4.62 & 18.11 & 4.28 & 18.54 & 4.73 & 17.31 & 3.99 & 8.67 & 6.17 & 12.48 & 3.85 & 16.92 & 3.44 & 10.54 & 3.61 \\
\hline
\end{tabular}


ioral flexibility in spatial tasks, requires the normal functioning of the hippocampus - and, particularly, of the dorsal hippocampus (Moser, Moser, \& Andersen, 1993), which contains more place cells than does the ventral portion (Poucet, Thinus-Blanc, \& Muller, 1994) - the DBA strain may specifically represent a model of dorsal hippocampal dysfunction. Indeed, this assumption is consistent with the finding that DBA mice present a reduced density of neurons in the dorsal hippocampus (Wimer et al., 1976). Nevertheless, the development of habituation in Sessions 2,3, and 4, as well as the blockade of habituation in reacting to spatial change, suggests that some residual hippocampal function is preserved in that strain. Additional experiments, aimed at examining the respective control exerted by the dorsal and the ventral part of the hippocampus on habituation and reactivity to objects, are necessary to better characterize the functional properties of the hippocampus in the DBA mouse.

\section{REFERENCES}

Ammassari-Teule, M., \& Caprioli, A. (1985). Spatial learning and memory, maze running strategies and cholinergic mechanisms in two inbred strains of mice. Behavioural Brain Research. 17, 9-16.

Barber, R. P., Vaughn, J. E., Wimer, R. E., \& Wimer, C. C. (1974). Genetically-associated variations in the distribution of dendate granule cell synapses upon the pyramidal cell dendrites in mouse hippocampus. Journal of Comparative Neurology, 156, 417-434.

BARNES, C. (1988). Spatial learning and memory processes: The search for their neurobiological mechanisms in the rat. Trends in Neurosciences, 11, 163-169.

CheAL, M. L. (1978). Stimulus-elicited investigation in the mongolian gerbil (Meriones unguiculatus). Journal of Biological Psychology, 20, 26-32.

Crusio, W. E., Schwegler, H., \& LiPP, H. P. (1987). Radial maze performance and structural variation of the hippocampus in mice: A correlation with mossy fiber distribution. Brain Research, 425, 182-185.

Douglas, R. J. (1975). The development of hippocampal function: Implications for theory and therapy. In R. L. Isaacson \& K. H. Pribram (Eds.), The hippocampus (Vol. 2, pp. 309-326). New York: Academic Press.

Douglas, R. J., \& IsaACSON, R. L. (1964). Hippocampal lesions and activity. Psychonomic Science, 1, 187-188.

Eichenbaum, H., Stewart, C., \& Morris, R. G. M. (1990). Hippocampal representation in place learning. Journal of Neuroscience, 10 , 3531-3542.

Ellen, P., Parko, E. M., Wages, C., Doherty, D., \& Hermann, T. (1982). Spatial problem solving by rats, exploration, and cognitive maps. Learning \& Motivation, 13, 81-94.

Gray, J. A. (1984). The hippocampus as an interface between cognition and emotion. In H. L. Roitblat, T. J. Bever, \& H. S. Terrace (Eds.), Animal cognition (pp. 607-626). Hillsdale, NJ: Erlbaum.

Gray, J. A., \& MCNaughton, N. (1983). Comparison between the behavioral effects of septal and hippocampal lesions: A review. Neuroscience \& Biobehavioral Reviews, 7, 119-188.

JOUBERT, A., \& VAUCLAIR, J. (1986). Reactions to novel objects in a troop of guinea baboons: Approach and manipulation. Behaviour, 96, $92-104$

Menzel, E. W., \& Menzel, C. R. (1979). Cognitive developmental and social aspects of responsiveness to novel objects in a family group of marmosets (Saguinus fuscicollis). Behaviour, 70, 251-278.

Misslin, R. (1983). Contribution neuroéthologique à l'étude des conduites néotiques chez la souris. Doctoral thesis, Université Louis Pasteur, Strasbourg, France.

Moser, E., Moser, M. B., \& Andersen, P. (1993). Spatial learning impairment paraltels the magnitude of dorsal hippocampal lesions but is hardly present following ventral lesions. Journal of Neuroscience, 13, 3916-3925.
O'Keefe, J., \& Nadel, L. (1978). The hippocampus as a cognitive map. Oxford: Oxford University Press, Clarendon Press.

Paylor, R., Baskal., L., \& Wehner, J. M. (1993). Behavioral dissociations between $\mathrm{C} 57 \mathrm{BL} / 6$ and $\mathrm{DBA} / 2$ mice on learning and memory tasks: A hippocampal dysfunction hypothesis. Psychobiology, 21, 11-26.

Paylor, R., Rudy, J. W., \& Wehner, J. M. (1991). Acute phorbol ester treatment improves spatial learning performance in rats. Behavioural Brain Research, 45, 189-193.

POuCET, B. (1989). Object exploration, habituation and response to a spatial change in rats following septal or medial frontal cortical damage. Behavioral Neuroscience, 103, 1009-1016.

Poucet, B., Chapuis, N., Durup, M., \& Thinus-Blanc, C. (1986). A study of exploratory behavior as an index of spatial knowledge in hamsters. Animal Learning \& Behavior, 14, 93-100.

Poucet, B., Thinus-Blanc, C., \& Muller, R. I. (1994). Place cells in the ventral hippocampus of rats. Neuroreport, 5, 2045-2048.

Rossi-Arnaud, C., \& Ammassari-Teule, M. (1992). Modifications of open field and novelty behaviours by hippocampal and amygdaloid lesions in two inbred strains of mice: Lack of strain $\times$ lesion interactions. Behavioural Processes, 27,155-164.

Rossi-Arnaud, C., Fagioli, S., \& Ammassari-Teule, M. (1991). Spatial learning in two inbred strains of mice: Genotype-dependent effect of amygdaioid and hippocampal lesions. Behavioural Brain Research, 45, 9-16.

Roullet, P., \& Lassalle, J. M. (1990). Genetic variation, hippocampal mossy fibres distribution and spatial representation in mice. Behavioural Brain Research, 41, 61-69.

Save, E., Buhot, M.-C., Foreman, N., Thinus-Blanc, C. (1992). Exploratory activity and response to a spatial change in rats with hippocampal and posterior parietal cortical lesions. Behavioural Brain Research, 47, 113-127.

Save, E., Poucet, B., Foreman, N., \& Buhot, M.-C. (1992). Object exploration and reactions to spatial change and nonspatial changes in hooded rats following damage to parietal cortex or dorsal hippocampus. Behavioral Neuroscience, 106, 447-456.

Sutherland, R. J., Chew, G. L., Baker, J. C., \& LingGard, R. C. (1987). Some limitations on the use of distal cues place navigation by rats. Psychobiology, 15, 48-57.

Thinus-Blanc, C., Bouzouba, L., Chaix, K., Chapuis, N., Durup, M., \& POUCET, B. (1987). A study of spatial parameters encoded during exploration in hamsters. Journal of Experimental Psychology: Animal Behavior Processes, 13, 418-427.

Thinus-Blanc, C., Durup, M., \& Poucet, B. (1992). The spatial parameters encoded by the hamster during exploration: A further study. Behavioural Processes, 26, 43-57.

Van Abeelen, J. H., \& Boersma, H. J. L. M. (1984). A genetically controlled hippocampal neurotransmitter system regulating exploratory behavior in inbred mice. Journal of Neurogenetics, 1,153-158.

Van Abeelen, J. H., \& Van den Heuvel, C. M. (1982). Behavioural responses to novelty in two inbred mouse strains after intrahippocampal naloxone and morphine. Behavioural Brain Research, 5, 199-207.

UPCHURCH, M., \& WEHNER, J. (1989). Inheritance of spatial learning ability in inbred mice: A classical genetic analysis. Behavioral Neuroscience, 103, 1251-1258.

Wehner, J. M., Sleight, S., \& UPChurch, M. (1990). Hippocampal protein kinase $\mathrm{C}$ activity is reduced in poor spatial learners. Brain Research, 523, 181-187.

WILZ, K. J., \& BOLTON R. L. (1971). Exploratory behavior in response to the spatial arrangement of familiar stimuli. Psychonomic Science, 24, $117-118$.

Wimer, R. E., Wimer, C. C., Vaughn, J. E., Barber, R. P., Balvanz, B. A., \& Chernow, C. R. (1976). The genetic organization of neuron number in Ammon's horns of house mouse. Brain Research, 118, 219-243.

Xavier, G. F., Stein, C., \& Bueno, O. F. A. (1990). Rats with hippocampal lesions do react to new stimuli but not to spatial change of known stimuli. Behavioral \& Neural Biology, 54, 117-183.

(Manuscript received October 25, 1994; revision accepted for publication May 2, 1995.) 